\title{
HUBUNGAN PENGETAHUAN LANSIA TERHADAP PEMANFAATAN POSYANDU DI WILAYAH KERJA UPTD PUSKESMAS SELEMADEG BARAT KABUPATEN TABANAN
}

\author{
Ade Linda Ayu Kristiana, Ni Ketut Martini, Ni Made Diaris \\ Program Studi Kesehatan Masyarakat, Fakultas Ilmu Kesehatan, Sains dan Teknologi, \\ Universitas Dhyana Pura \\ Email: adelindaac@gmail.com
}

\begin{abstract}
ABSTRAK
Posyandu Lansia didirikan untuk menjaga kesehatan lansia, karena usia lanjut sangat rentan terhadap suatu penyakit. Namun masih banyak lansia yang tidak memanfaatkan pelayanan posyandu. Tujuan penelitian ini adalah untuk mengetahui hubungan pengetahuan lansia terhadap pemanfaatan posyandu. Populasi dalam penelitian ini adalah lansia yang terdaftar di Posyandu Lansia Desa Lumbung, Kecamatan Selemadeg Barat yang berjumlah 324 orang. Sampel yang diambil berjumlah 83 orang yang diperoleh dengan menggunakan teknik simple random sampling yang bersifat observasional dengan pendekatan cross sectional. Instrumen penelitian yang digunakan adalah kuesioner. Data dalam penelitian ini diolah dengan menggunakan uji statistik chi-square dengan tingkat kemaknaan $=0,05$. Dari hasil penelitian diperoleh bahwa ada hubungan yang signifikan antara pengetahuan lansia terhadap pemanfaatan posyandu $(\mathrm{P}=0,001)$. Saran yang dianjurkan yaitu bagi instansi kesehatan, agar lebih meningkatkan penyuluhan kesehatan dan membuat suatu advokasi atau aturan tegas dalam hal pemanfaatan posyandu.
\end{abstract}

Kata Kunci : lansia, pengetahuan, pemanfaatan posyandu

\begin{abstract}
Elderly Posyandu is a community program Health Center fot the elderly with the aim that the elderly are ready to face old age with independence and health. The low coverage of the use of Elderly Posyandu services has an impact on the elderly themselves, the community, and the government. Elderly people will experience a physical and mental decline, economic, social, and one of the most important problems is a health problem so that an optimal health approach and guidance is needed. The purpose of this study was to determine the relationship of knowledge of the elderly to the use of posyandu. The population in this study was the elderly who were registered at the Elderly Village Posyandu in Selemadeg Barat District, which numbered 324 people. The samples taken were 83 people obtained by using observational simple random sampling technique with a cross sectional approach. The research instrument used was a questionnaire. The data in this study were processed using chi-square test statistics with significance level $=0.05$. From the results of the study, it was found that there was a significant relationship between the knowledge of the elderly towards the use of posyandu $(P=0.001)$. The recommendation health agencies, is to further improve health education and make an advocacy or strict rules in the use of posyandu.
\end{abstract}

Keywords: elderly, knowledge, utilization of posyandu

\section{PENDAHULUAN}

Umur Harapan Hidup (UHH) merupakan salah satu indikator dalam kesehatan masyarakat. Meningkatnya UHH menunjukkan tingginya derajat kesehatan masyarakat. UHH dijadikan indikator keberhasilan pembangunan sekaligus sebagai tantangan dalam pembangunan, selain itu menjadi alat untuk mengevaluasi kinerja pemerintah dalam meningkatkan kesejahteraan penduduk secara umum dan meningkatkan derajat kesehatan pada khususnya. Semakin meningkatnya UHH maka jumlah lanjut usia (Lansia) juga semakin bertambah (Kemenkes RI, 2017).
Di kawasan Asia Tenggara populasi Lansia sebesar 8\% atau sekitar 142 juta jiwa. Pada tahun 2050 diperkirakan populasi Lansia meningkat 3 kali lipat dari tahun 2013. Pada tahun 2000 jumlah Lansia sekitar 5,300,000 $(7,4 \%)$ dari total populasi, sedangkan pada tahun 2010 jumlah Lansia 24,000,000 (9,77\%) dari total populasi, dan tahun 2020 diperkirakan jumlah Lansia mencapai 28,800,000 (11,34\%) dari total populasi. Sedangkan di Indonesia sendiri pada tahun 2020 diperkirakan jumlah Lansia sekitar 80.000.000 (Kemenkes RI, 2013). 
Salah satu permasalahan yang sangat mendasar pada lansia adalah masalah kesehatan sehingga diperlukan pembinaan kesehatan pada kelompok pra lansia dan lansia, bahkan sejak usia dini. Masalah kesehatan yang dialami oleh lansia adalah munculnya penyakit degeneratif akibat proses penuaan, gangguan gizi (malnutrisi), penyakit infeksi serta masalah kesehatan gigi dan mulut(Kemenkes RI, 2015).

Dalam Peningkatan kualitas pelayanan kesehatan lansia di fasilitas kesehatan telah diterbitkan Peraturan Menteri Kesehatan Nomor 79 tahun 2014 tentang Penyelenggaraan Pelayanan Kesehatan Geriatri di Rumah Sakit yang telah masuk ke dalam penilaian Standar Nasional Akreditasi Rumah Sakit (SNARS) dan Peraturan Menteri Kesehatan Nomor 67 tahun 2015 tentang Penyelenggaraan Pelayanan Kesehatan Lanjut Usia di Puskesmas. Selain itu, diterbitkan juga Peraturan Menteri Kesehatan Nomor 25 tahun 2016 tentang Rencana Aksi Nasional Kesehatan Lanjut Usia Tahun 2016-2019 untuk memberikan acuan bagi pemerintah pusat, pemerintah daerah, dan pemangku kepentingan lain berupa langkah-langkah konkrit yang harus dilaksanakan secara berkesinambungan dalam rangka peningkatan derajat kesehatan lansia untuk mencapai lansia yang sehat, mandiri, aktif, produktif dan berdayaguna bagi keluarga dan masyarakat (Kemenkes RI, 2017).

Salah satu upaya untuk memberdayakan lanjut usia di masyarakat adalah melalui pembentukan dan pembinaan kelompok lansia di beberapa daerah disebut dengan Kelompok Usia Lanjut (Poksila), Pos Pelayanan Terpadu Lanjut Usia (Posyandu Lansia) atau Pos Pembinaan Terpadu Lanjut Usia (Posbindu Lansia). Pelaksanaan kelompok lansia ini selain mendorong peran aktif masyarakat dan Lembaga Swadaya Masyarakat, juga harus melibatkan lintas sektor terkait. Untuk pelayanan di masyarakat, jumlah Posyandu Lansia/Posbindu yang dibina oleh Puskesmas mencapai 80.353 kelompok dan tersebar di semua provinsi (Kemenkes RI, 2017).

Posyandu Lansia merupakan program puskesmas dengan sasarannya adalah lansia dengan tujuan agar lansia siap mengahadapi usia lanjut dengan mandiri dan sehat. Pemeriksaan kesehatan berkala dan konsultasi kesehatan pada lansia merupakan kunci keberhasilan dari upaya pemeliharaan kesehatan kelompok lansia, walaupun tidak sedang sakit ataupun memiliki keluhan, kelompok lansia perlu untuk memeriksakan kesehatannya secara berkala, karena keadaan penyakit yang ada dapat dideteksi lebih dini dan faktor yang berisiko dapat segera dicegah.
Rendahnya cakupan pemanfaatan pelayanan Posyandu Lansia berdampak pada lansia itu sendiri, masyarakat, dan pemerintah. Pada lansia itu sendiri, mereka akan mengalami suatu kemunduran fisik dan mental, ekonomi, sosial, dan salah satu masalah yang sangat penting adalah masalah kesehatan sehingga diperlukan pendekatan dan pembinaan kesehatan yang optimal dan juga akan berakibat kepada pembangunan nasional yang telah direncanakan dan hasilnya tidak sesuai dengan harapan pembangunan itu sendiri. Tujuan dari penelitian ini adalah Mengetahui hubungan pengetahuan lansia terhadap pemanfaatan pelayanan posyandu lansia di wilayah kerja UPTD Puskesmas Selemadeg Barat.

\section{METODE PENELITIAN}

Penelitian ini menggunakan metode kuantitatif. Jenis penelitian ini bersifat observasional dengan pendekatan cross sectional. Penelitian ini dilakukan pengumpulan dta dilakukan pada 11 Februari sampai dengan tanggal 11 Maret tahun 2019 di Desa Lumbung, Wilayah Kerja UPTD Puskesmas Selemadeg Barat, Kabupate Tabanan. Populasi pada penelitian ini adalah lansia yang terdaftar di Posyandu Lansia Desa Lumbung, kecamatan Selemadeg Barat yang berjumlah 324 lansia. Sampel yang digunakan sebanyak 83 orang. Variabel bebas ialah pengetahuan lansia, sedangkan variabel terikat ialah pemanfaatan posyandu lansia. Instrumen yg digunakan pada penelitian ini yaitu dalam bentuk kuesioner pertanyaan-pertanyaan yang berhubungan dengan variabel penelitian yang harus dijawab responden. Untuk mengetahui hubungan variabel independen (pengetahuan lansia) dengan variabel dependen (pemanfaatan posyandu lansia) maka digunakan statistik uji ChiSquare dengan derajat kepercayaan $95 \%(\alpha=$ $0,05)$.

\section{HASIL DAN PEMBAHASAN \\ Analisis Univariat}

Data penelitian ini diolah melalui analisis univariat dan bivariat. Analisis univariat berisi hasil distribusi frekuensi responden berdasarkan karateristik pendidikan dan jenis kelamin terdapat pada Tabel 1 .

Tabel 1 Distribusi Berdasarkan Jenis Kelamin

\begin{tabular}{ccc}
\hline Jenis Kelamin & $\begin{array}{c}\text { Jumlah Lansia } \\
\text { (Orang) }\end{array}$ & $\begin{array}{c}\text { Presentase } \\
(\%)\end{array}$ \\
\hline Laki-Laki & 63 & 75,9 \\
Perempuan & 20 & 24,1 \\
\hline Jumlah & 83 & 100 \\
\hline
\end{tabular}

Berdasarkan tabel 1 bahwa lansia yang 
berjenis kelamin laki-laki sebanyak 63 orang $(75,9 \%)$, dan yang berjenis kelamin perempuan sebanyak 20 orang $(24,1 \%)$. Jika ditinjau dari jenis kelamin, semua lansia baik laki-laki maupun perempuan harus memanfaatkan pelayanan posyandu lansia, karena manfaatnya bukan hanya bagi lansia saja tetapi keluarga juga dapat manfaat dari pelayanan posyandu lansia $(\mathrm{G}$, Ibrahim Dermawan. 2017).

Pada tabel 2. bahwa lansia yang berpendidikan dasar sebanyak 42 orang $(50,6 \%)$, yang berpendidikan menengah sebanyak 28 orang $(33,7 \%)$, dan yang berpendidikan tinggi sebanyak 13 orang $(15,7 \%)$.

Tabel 2 Distribusi Berdasarkan Pendidikan Lansia

\begin{tabular}{ccc}
\hline Pendidikan & $\begin{array}{c}\text { Jumlah Lansia } \\
\text { (Orang) }\end{array}$ & $\begin{array}{c}\text { Presentase } \\
(\%)\end{array}$ \\
\hline Dasar & 42 & 50,6 \\
Menengah & 28 & 33,7 \\
Tinggi & 13 & 15,7 \\
\hline Jumlah & 83 & 100 \\
\hline
\end{tabular}

Pada tabel 3. pengetahuan lansia pada posyandu dibagi menjadi tiga kategori yaitu baik, cukup dan kurang. Berdasarkan penelitian yang dilakukan, dari 83 Lansia pada Posyandu sebanyak 55 orang $(66,3 \%)$ memiliki pengetahuan baik, sebanyak 19 orang (22,9\%) memiliki pengetahuan cukup dan sebanyak 9 orang $(10,8 \%)$ memiliki pengetahuan kurang. Pengetahuan lansia akan manfaat Posyandu dapat diperoleh dari pengalaman pribadi dalam kehidupan sehari-harinya. Dengan menghadiri kegiatan Posyandu, lansia akan mendapatkan penyuluhan tentang bagaimana cara hidup sehat. Dengan pengalaman ini, pengetahuan lansia menjadi meningkat, yang menjadi dasar pembentukan sikap dan dapat mendorong minat atau motivasi mereka untuk selalu mengikuti kegiatan Posyandu lansia (Trisnayanti. et al. 2014).

Tabel 3 Distribusi Berdasarkan Pengetahuan

\begin{tabular}{ccc}
\hline Pengetahuan & $\begin{array}{c}\text { Jumlah Lansia } \\
\text { (Orang) }\end{array}$ & $\begin{array}{c}\text { Presentase } \\
(\%)\end{array}$ \\
\hline Baik & 55 & 66,3 \\
Cukup & 19 & 22,9 \\
Kurang & 9 & 10,8 \\
\hline Jumlah & 83 & 100 \\
\hline
\end{tabular}

Berdasarkan tabel 4 pemanfaatan layanan posyandu dibagi menjadi dua kategori yaitu aktif dan tidak aktif. Hasil penelitian layanan posyandu menunjukkan dari 83 lansia di posyandu sebanyak $58(69,9 \%)$ aktif mengikuti kegiatan posyandu dan $25(30,1 \%)$ tidak aktif mengikuti kegiatan posyandu.

Tabel 4 Distribusi Menurut Pemanfaatan Posyandu

\begin{tabular}{ccc}
\hline $\begin{array}{c}\text { Pemanfaatan } \\
\text { Layanan } \\
\text { Posyandu }\end{array}$ & $\begin{array}{c}\text { Jumlah Lansia } \\
\text { (Orang) }\end{array}$ & $\begin{array}{c}\text { Presentase } \\
(\%)\end{array}$ \\
\hline $\begin{array}{c}\text { Aktiv } \\
(>8 \text { kali/tahun }) \\
\text { Tidak Aktif } \\
(<8 \text { kali/tahun) }\end{array}$ & 58 & 69,9 \\
\hline Jumlah & 25 & 30,1 \\
\hline
\end{tabular}

\section{Analisis Bivariat}

Analisis bivariat digunakan untuk mengetahui hubungan antar variabel bebas dan variabel terikat yaitu pengetahuan terhadap pemanfaatan posyandu di Wilayah Kerja Uptd Puskesmas Selemadeg Barat, Kabupaten Tabanan.

Tabel 5 Hubungan Pengetahuan Terhadap Pemanfaatan Posyandu Di Wilayah Kerja Uptd Puskesmas Selemadeg Barat, Kabupaten Tabanan.

\begin{tabular}{|c|c|c|c|c|c|c|c|}
\hline \multirow{3}{*}{$\begin{array}{c}\text { Pengetahuan } \\
\text { Lansia } \\
\end{array}$} & \multicolumn{5}{|c|}{ Pemanfaatan Layanan } & & \multirow[t]{3}{*}{ Nilai P } \\
\hline & \multicolumn{2}{|c|}{ Aktif } & \multicolumn{2}{|c|}{ Tidak Aktif } & \multirow[t]{2}{*}{$\mathrm{N}$} & \multirow[t]{2}{*}{$\%$} & \\
\hline & $\mathrm{N}$ & $\%$ & $\mathrm{~N}$ & $\%$ & & & \\
\hline \multirow[t]{2}{*}{ Baik } & 4 & 81,8 & 1 & 18,2 & 55 & 100 & $\mathrm{P}=0,00$ \\
\hline & 5 & & 0 & & & & 1 \\
\hline \multirow[t]{2}{*}{ Cukup } & 1 & 57,9 & 8 & 42,1 & 19 & 100 & \\
\hline & 1 & & & & & & \\
\hline Kurang & 2 & 22,2 & 7 & 77,8 & 9 & 100 & \\
\hline \multirow[t]{2}{*}{ Jumlah } & 5 & 69,9 & 2 & 30,1 & 83 & 100 & \\
\hline & 8 & & 5 & & & & \\
\hline
\end{tabular}

Tabel 5 menunjukkan hasil bahwa dari 55 lansia yang memiliki pengetahuan baik sebanyak 45 lansia $(81,8 \%)$ aktif mengikuti kegiatan posyandu dan sebanyak 10 lansia $(18,2 \%)$ tidak aktif mengikuti kegiatan posyandu. Sedangkan, dari 
19 lansia yang memiliki pengetahuan cukup sebanyak 11 lansia $(57,9 \%)$ aktif mengikuti kegiatan posyandu dan sebanyak 8 lansia $(42,2 \%)$ tidak aktif mengikuti kegiatan posyandu dan dari 9 lansia yang memiliki pengetahuan kurang sebanyak 2 lansia (22,2\%) aktif mengikuti kegiatan posyandu dan sebanyak 7 lansia $(77,8 \%)$ tidak aktif mengikuti kegiatan posyandu.

Berdasarkan analisis statistik dengan mempergunakan uji Chi - Square diperoleh nilai $\mathrm{P}$ sebesar $0.001<0.05$ maka dapat disimpulkan Ho ditolak karena adanya hubungan yang signifikan antara pengetahuan lansia terhadap pemanfaatan posyandu di Wilayah kerja Uptd Puskesmas Selemadeg Barat, Kabupaten Tabanan.

\section{SIMPULAN}

Dapat disimpulkan bahwa ada hubungan yang signifikan antara pengetahuan lansia terhadap pemanfaatan posyandu di Wilayah Kerja Uptd Puskesmas Selemadeg Barat, Kabupaten Tabanan dengan nilai $\mathrm{p}=0,001(\mathrm{p}<0,05)$.

\section{DAFTAR PUSTAKA}

G. Dermawan, Ilham. 2017. Faktor-Faktor Yang Berpengaruh Terhadap Pemanfaatan Pelayanan Posyandu Lansia Di Wilayah Kerja Puskemas Glugur Darat Medan. Skripsi. Universitas Sumatera Utara

Trinayanti, Ayu Chandra. 2014. Pengaruh Edukasi Tentang Program Posyandu Lansia Terhadap Keikutsertaan Lansia Dalam Mengikuti Senam Lansia Di Wilayah Kerja Puskesmas I Selemadeg Barat. Skripsi. STIKES Wira Medika PPNI Bali.

Kemenkes RI. 2013. Pusat Data dan Informasi: Gambaran Kesehatan Lanjut Usia di Indonesia.Kementerian Kesehatan RI, Jakarta

Kemenkes RI. 2015. Rencana Strategis Kementerian Kesehatan Tahun 2015-2019. Kementerian Kesehatan RI, Jakarta.

Kemenkes RI. 2017. Peningkatan Derajat Kesehtan Lansia.Kementrian Kesehatan RI. Jakarta. 